\title{
TOOTH PROFILE MODIFICATION AND SIMULATION ANALYSIS OF INVOLUTE SPUR GEAR
}

\author{
Li, X. Y.*; Wang, N. N.*; Lv, Y. G. ; Zeng, Q. L. ${ }^{*} \&$ Hidenori, K. ${ }^{* *}$ \\ ${ }^{*}$ College of Mechanical and Electronic Engineering, Shandong University of Science and Technology, \\ Qingdao, 266590, China \\ ${ }^{* *}$ PSC Co., Ltd. Kanagawa-ken, 225-0013, Japan \\ E-Mail: lixueyi07@tsinghua.org.cn
}

\begin{abstract}
The spur gear mechanism with the standard involute profile may generate noise and shock because of tooth structure and transmission principle, resulting in substantial transmission errors. These limitations can be effectively resolved through tooth profile modification. To address the defects and deficiencies of existing tooth profile modification methods in terms of the modification principle and effect assessment, this study proposes an adaptive method of tooth profile modification with alterable tooth profile for spur gear mechanism. A corresponding simulation method for evaluating the modification performance of the gear transmission was introduced in detail. The final shape parameters of the modification profile were determined by orthogonal experiments. Simulation results show that tooth profile modification for involute spur gear does not affect bending and contact stresses. The process can also effectively improve the stability of transmission. The impact and noise of gear pair with tooth profile modification significantly decreased during meshing. The proposed method exhibits stronger adaptability compared with other existing methods of tooth profile modification. Moreover, the proposed method can adaptively determine the optimal modification parameters based on different conditions and obtain the ideal modification effect.

(Received in January 2016, accepted in June 2016. This paper was with the authors 2 months for 1 revision.)
\end{abstract}

Key Words: Tooth Profile Modification, Transmission Error, Impact, Parametric Modelling, Simulation Analysis

\section{INTRODUCTION}

Gear transmission is an important method used to transmit power in mechanisms. Gear units, which are key components in load bearing and power transmission, are widely used in production practices. Load carrying capacity and transmission smoothness seriously affect the performance of the equipment. Particularly, meshing impact is inevitable when the spur gear pair transmits power. Transmission error (TE) is caused by elastic deformation of gear teeth, thermal deformation, assembly error, and machining error. The fluctuation of TE may lead to generation of vibrations and noises by the gear mechanism, resulting in serious issues, such as unexpected damage, abnormal working, and declined accuracy. Tooth profile modification, which can correct the deformed tooth profile and substantially decrease the meshing impact and the fluctuation of $\mathrm{TE}$, is the most effective solution in reducing vibrations and noises in gear units. However, existing methods are not always ideal for different spur gear pairs. Moreover, the profile of gear tooth is no longer the standard involute after modification. Hence, calculating the strength of the modified gear and analysing the working performance of the gear must be performed.

\section{STATE OF THE ART}

Numerous researchers have conducted studies on the limitation problem and application of tooth profile modification. Kim et al. [1] proposed an original method for calculating the amount of modification. Magalhaes et al. [2, 3] and Gevigney et al. [4] mainly evaluated the 
effects of tooth profile modification on power loss in gear system. Another study investigated tip relief [5]. Shanmugasundaram and Muthusamy [6] proposed a novel method for improving the performance of gear transmission, and the results confirmed that gears with circular root filet exhibit higher bending strength than that of standard trochoidal root filet. However, diminishing the instability of transmission and vibrations was not considered in these studies.

The relationship of dynamic mesh forces and TE was theoretically investigated in the literature [7]. Tooth profile modification can effectively reduce the dynamic load. Ghosh and Chakraborty [8] applied tooth profile modification to improve the instability of a gear system. Subramanian and Srinivasan [9] conducted a comparative and experimental analysis for spur gear, and generating a groove at the root of the gear can improve the vibration phenomenon. However, modification parameters have not been optimized yet.

Bahk and Parker [10] discussed the effects of different amounts of tooth profile modification on gear transmission. However, they didn't consider the influence of other modification parameters. In literature [11], optimization experiments were conducted for bevel gears, and the optimal amount and length of modifications were determined by genetic algorithm while disregarding the influence of the shape parameters of benchmark curve for modification. Artoni et al. [12] and Ghribi et al. [13] proposed a robust modification method. However, the effectiveness of this algorithm was not verified by experiments.

Furthermore, the transmission performance differs from the standard gear pair after modification. Thus, conducting simulations and evaluating the performance of the gear pair with tooth profile modification are difficult. Sachidananda et al. [14] proposed a method to calculate the contact stress of the modified gear pair. However, this method is not suitable for calculating the bending stress. Barbieri et al. [15] explored the performance of the gear pair with tooth profile modification by performing Loaded Tooth Contact Analysis. Numerous researchers like Tesfahunegn [16] established models of modified gear pair in Pro/E while analysing it in other software, which may lead to data loss.

With regard to the shortcomings of the previous studies, the purpose of this work is to solve the preceding problems. In this paper, a complete set of tooth profile modification and simulation analysis method for spur gear pairs were proposed. The modification parameters of the gear pair can be optimized by using the orthogonal experiment. The meshing performance of the modified gear pair can be obtained by the transient meshing simulation analysis.

The rest of this thesis is organized as follows. Section 3 mainly introduces the theory and methods used in this work. Section 4 discusses the results obtained from simulation and comparative analysis and modification parameters are optimized in this section. Finally, the conclusions are summarized in Section 5.

\section{METHODOLOGY}

\subsection{Necessity of tooth profile modification and assessment criteria}

The transmission ratio of a gear pair should be stable and the base pitch of the two gears should be equal based on the principle of gear meshing [17]. Essentially, the transmission ratio is variable and the base pitch of the two gears is not equal because of the machining error, assembly error, and tooth deformation. This phenomenon usually results in nonstationary transmission and the obvious variability of TE.

As shown in Fig. 1 a, if the actual base pitch of the drive gear $p_{b 1}$ is longer than the actual base pitch of the driven gear $p_{b 2}$, the tooth pair II would not mesh in time because of the difference $\Delta p=p_{b 1}-p_{b 2}$. Thus, tooth pair I has to continue meshing alone and the tooth tip of the drive gear scrapes the root of the driven gear until tooth pair II participates in the meshing. The impact is generated from the middle part of the tooth when tooth pair II begins to mesh. Simultaneously, the actual transmission ratio is changed and the rotate speed of the driven 
gear is not constant. Thus, the TE of the gear pair has a massive fluctuation. As described in Fig. $1 \mathrm{~b}$, if the actual base pitch of the drive gear is shorter than the driven gear, which means $p_{b 1}<p_{b 2}$, tooth pair II would not mesh in at the theoretical start point $B_{2}$ because of the difference $\Delta p=p_{b 2}-p_{b 1}$. Instead, the tooth pair would mesh in at point $C$ in advance, which is outside the theoretical meshing line. In this case, the tooth tip of the driven gear knocks into the root of the drive gear and the tooth of the driven gear scrapes the surface of the drive gear. The real transmission ratio of the gear pair changes in the meshing process. The preceding phenomenon described is called meshing impact.

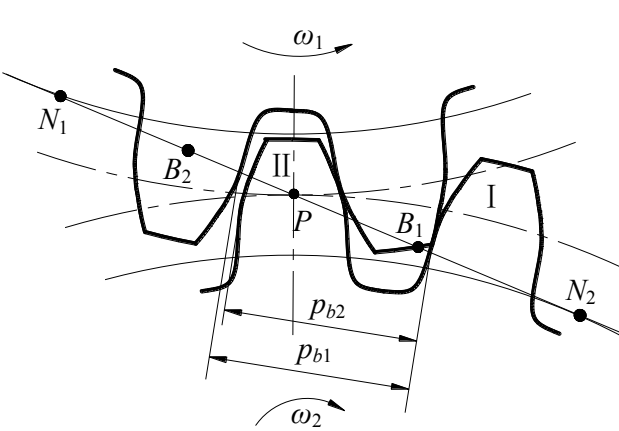

a) Gear engagement when $p_{b 1}>p_{b 2}$

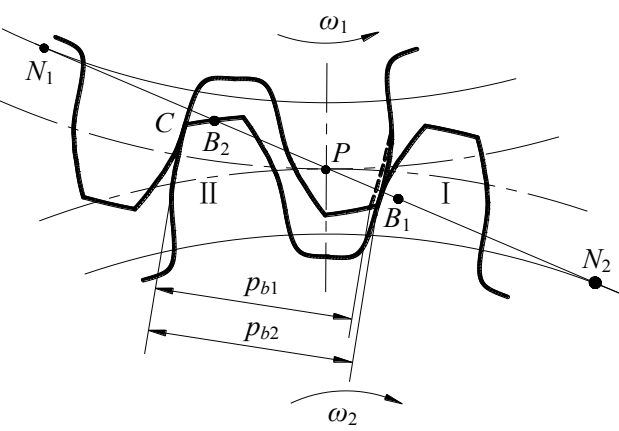

b) Gear engagement when $p_{b 1}<p_{b 2}$

Figure 1: Schematic of actual gear engagement.

Based on the preceding analysis, TE is inevitable and constantly changing in the spur gear transmission with standard involute profile. The value of TE $\Delta(t)$ in the transmission process is as follows:

$$
\Delta(t)=\varphi_{2}(t)-\frac{z_{1}}{z_{2}} \cdot \varphi_{1}(t)
$$

In Eq. (1), $z_{1}$ and $z_{2}$ represents the teeth number of the drive gear and the driven gear respectively, $\varphi_{1}(t)$ is the rotation angle of the drive gear, and $\varphi_{2}(t)$ is the rotation angle of the driven gear.

In addition, using the fluctuation of $\mathrm{TE}$ to evaluate the non-stationary transmission performance is very important because the fluctuation is associated with vibrations and noises in the gear mechanism rather than TE itself [18]. The standard deviation of TE in the meshing process was calculated based on Eq. (2) to describe the fluctuation of TE.

$$
\sigma=\sqrt{\frac{1}{n} \sum_{i=1}^{n}\left(\Delta_{i}(t)-\frac{1}{n} \sum_{j=1}^{n} \Delta_{j}(t)\right)^{2}}
$$

In Eq. (2), $n$ is the total number of TE calculated, and $\Delta_{i}(t)$, as well as $\Delta_{j}(t)$, represent the value of TE which changes with time.

In gear transmission, with the exception of the previously mentioned meshing impact, an impact load exists when single and double teeth pair alternately mesh in the gear pair wherein contact ratio $\varepsilon$ is bigger than 1. As shown in Fig. 2, point $B_{2}$ represents the initial point of meshing, point $B_{1}$ represents the ending point of tooth meshing and points $D_{1}$ as well as $D_{2}$ are alternate points of single and double teeth meshing, respectively. A double teeth meshing status is when the gear pair meshes in the $B_{1} D_{1}$ and $B_{2} D_{2}$ region, whereas the gear pair is in the single tooth meshing status in the region of $D_{1} D_{2}$. The load on the gear during the transmission varies, along with a few abrupt changes. Essentially, the load on any gear tooth looks like the broken line as $a b c d e f g h$ in Fig. 2 . The value at point $b$ is approximately $40 \%$ of the maximum and the value at point $c$ (alternate point) is approximately $60 \%$ of the maximum. The load on the teeth is the maximum (segment of $d e$ ). In conclusion, the load may generate abrupt changes during the meshing process. The trend of the load on the gear tooth is more 
stable if the spur gear pair is modified, which indicates that the load on the meshing tooth gradually increases when the tooth pair starts to mesh and gradually decreases when the tooth pair exits the meshing.

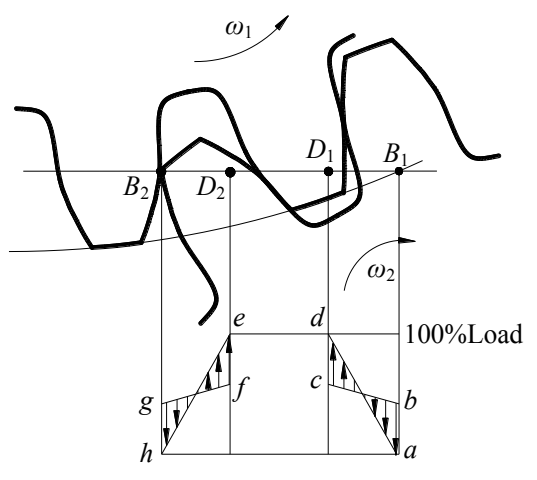

Figure 2: Tooth load distribution.

Hence, a precise acquisition of the load distribution in the process of meshing is another important standard to evaluate the modification effect.

\subsection{Tooth profile modification}

Tip relief is adopted for gear teeth in this study, as described in Fig. 3.

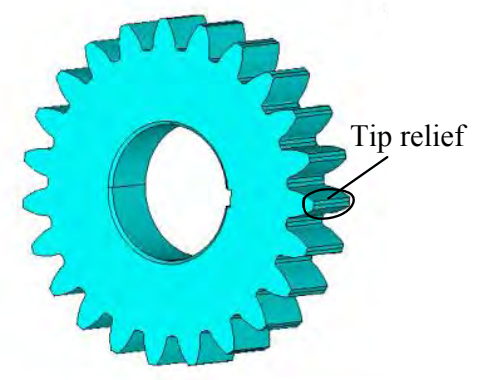

Figure 3: Tip relief.

The length of modification, the maximum amount $\Delta_{\max }$, and the benchmark curve are three principal parameters of tooth profile modification. The modified gear tooth is shown in Fig. 4.

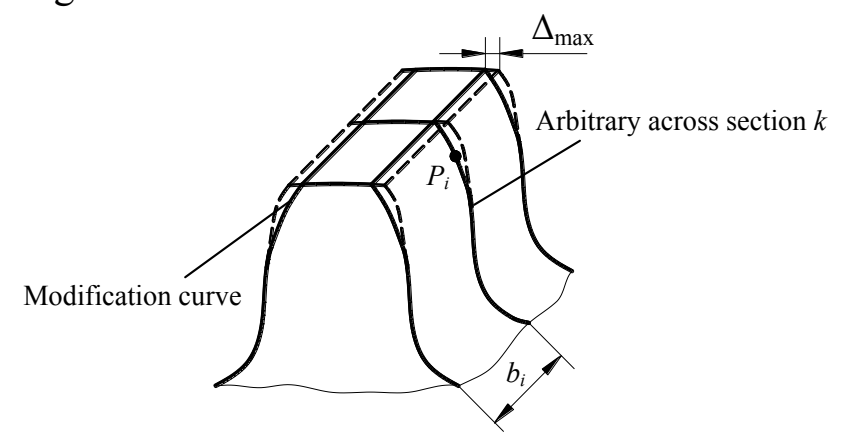

Figure 4: Diagram of tooth profile modification.

The length of modification is divided into two types: long modification and short modification. Long modification refers to correcting the tooth from the tip to the first alternate point, whereas the length of short modification is half of it. In this study, the long modification was adopted.

Numerous companies and researchers proposed numerous experiential equations with regard to calculating the maximum amount of modification. However, there are substantial 
deviations between these equations. Therefore, a theoretical equation is used to calculate the maximum amount of modification $\Delta_{\max }$ in this study, as shown in Eq. (3):

$$
\Delta_{\max }=\delta+\delta_{\theta}+\delta_{m},
$$

where $\delta$ is the value of tooth deformation, $\delta_{\theta}$ is the thermal deformation, and $\delta_{m}$ is the error of assembly and machining. The maximum amount of modification in this study was calculated as a reference to establish the foundation for subsequent optimization experiments.

A composite curve with indefinite parameters was proposed in this study to determine more suitable benchmark curves for gear pair. The amount of modification at any point on the benchmark curve is shown in Eq. (4):

$$
\Delta=\Delta_{\max } \cdot\left\lfloor\lambda\left(\frac{x}{l}\right)^{\gamma}+(1-\lambda) \cdot\left(\frac{x}{l}\right)^{\beta}\right\rfloor
$$

In Eq. (4), $x$ represents the length between the specified point and the initial modification point, $\mathrm{mm} . l$ is the total length from the initial point to the tip point on the meshing line, $\mathrm{mm}$. $\lambda$ is the superposition coefficient, $0 \leq \lambda \leq 1 . \gamma$ and $\beta$ are power, and $1 \leq \gamma \leq 3,1 \leq \beta \leq 3$. Any shape of benchmark curves for modification can be obtained by adjusting these parameters. For instance, when $\gamma=\beta=1$, the benchmark curve is a straight line, whereas when $\gamma=\beta=1.22$, it is a Hidaka-Terauchi curve. And when $\gamma=\beta=1.5$, it is a Walker's curve, whereas when $\lambda=0.44, \gamma=1$ and $\beta=2$, it is an Akiyama-Utagawa curve. Orthogonal experiments were conducted to acquire the appropriate benchmark curve for modification in this research and to optimize the corresponding parameters.

The tooth surface of a modified gear becomes a complex surface comprising involute tooth surface and modified surface. If point $\mathrm{P}_{i}$ is located at any $k$-section along the tooth width direction as shown in Fig. 4, the coordinates of this point are as follows:

$$
\left\{\begin{array}{l}
\rho_{k i}=\sqrt{r_{a}^{2}+\left(l-x_{i}\right)^{2}-2 r_{a} \cdot\left(l-x_{i}\right) \cos \left(\frac{\pi}{2}-\alpha_{a}\right)} \\
\varphi_{k i}=\left(\theta_{1 k i}+\theta_{2 k i}-\theta_{3 k i}\right) \cdot \frac{180}{\pi} \\
z_{k i}=z_{k}
\end{array}\right.
$$

where $r_{a}$ is the radius of the tip circle, $l$ is the total length of modification, $\alpha_{a}$ is the pressure angle of the tip circle, $x_{i}$ is the modification length of this point, $z_{k}$ is the axial coordinate of this section, and $\theta_{1 k i}, \theta_{2 k i}$, and $\theta_{3 k i}$ are calculated based on Eq. (6):

$$
\left\{\begin{array}{l}
\theta_{1 k i}=\tan \alpha_{k i}-\alpha_{k i} \\
\theta_{2 k i}=\frac{s_{r}}{2 r}-\theta_{1 k i}+\theta \\
\theta_{3 k i}=\arctan \left(\frac{\rho_{k i} \cdot \sin \theta_{2 k i}-\Delta_{i}}{\rho_{k i} \cos \theta_{2 k i}}\right)
\end{array}\right.
$$

In the equation, $s_{\gamma}$ is the tooth thickness at the reference circle, $r$ is the radius of the reference circle, $\theta$ is the generating angle of the reference circle, and $\alpha_{k i}$ is shown in Eq. (7):

$$
\alpha_{k i}=\alpha_{a}-\arcsin \frac{\sin \left(\frac{\pi}{2}-\alpha_{a}\right) \cdot\left(l-x_{i}\right)}{\rho_{k i}}
$$


The component without modification is a standard involute surface and the coordinates of the points on the surface are available in numerous references.

\subsection{Modelling of the spur gear pair with tooth profile modification}

Simulation analysis was performed based on finite element analysis (FEA) in this study to obtain the meshing characteristics of the gear pair with tooth profile modification. Before that, finite element model of the gear pair with tooth profile modification should be built as follows.

Based on the preceding equations, the coordinates of the point on the tooth surface can be calculated. Thus, the dot matrix of the modified tooth surface can be acquired. Based on cubic B-spline interpolation, the modified tooth surface can be established. Thus, the model of modification gear pair can be accurately built and assembled in ANSYS. The model was simplified to reduce the quantity of calculation. In addition, mesh generation was conducted based on the simplified model. The finite element model of the modified gear pair was established by applying loads and constraints on the mesh model, as shown in Fig. 5.

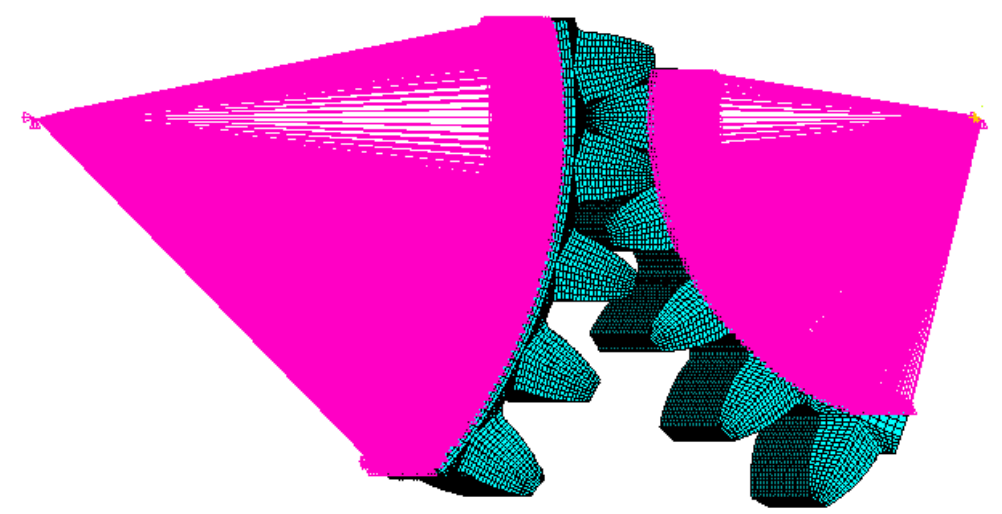

Figure 5: Finite element modelling of the gear pair with tooth profile modification.

The preceding modelling process can be performed by parametric programming. The transmission performances of the gear pair with tooth profile modification, such as stresses and load distribution, can be obtained via simulation analysis.

\subsection{Optimization of profile modification}

The orthogonal design method is a kind of mathematical statistics to solve multi-factor and multi-level problems arranged by an orthogonal table. Numerous researchers like Xie et al. [19] designed their experiments using the orthogonal method. In this study, orthogonal experiments can be conducted for numerous times until a set of test results at least meets the requirement. The modification requires that the standard deviation of TE during the meshing process should be less than or equal to the required value. There are four factors found in Eq. (4) which influence the modification effects in this study. These factors are $\Delta_{\text {max }}^{\prime}, \lambda, \gamma$ as well as $\beta$. Every factor was divided into five levels at first experiment. The orthogonal table $\mathrm{L}_{25}\left(5^{6}\right)$ was used to improve the experimental efficiency.

The orthogonal experiments were conducted based on the preceding simulation analysis. The ideal modification can be obtained by comparing the results.

\subsection{Experimental measurement for transmission error}

After completing the orthogonal experiments, the ideal modification method can be verified by the experimental measurement to detect TE. The load on the tooth surface is difficult to detect in practice. Therefore, the experimental measurement for obtaining load distribution was not conducted in this study. The experimental equipment is shown in Fig. 6. 


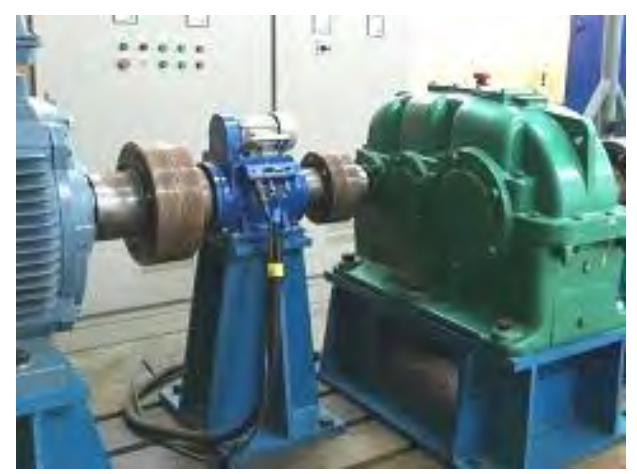

Figure 6: Experimental equipment.

The equipment comprises a detection equipment, gearbox, analysis device, and so on. The trial-produced gear pair with tooth profile modification should be assembled in the gear box to detect the rotation angles of the drive gear and driven gear respectively by using two grating reading heads and precise extraction by the detection system. Thereafter, the timevarying data regarding TE can be calculated based on Eq. (1), and the fluctuation of TE intuitively reflects the modification effect.

\section{RESULT ANALYSIS}

A gear pair in a mine reducer was selected to simulate the tooth profile modification and the meshing performance of the modified gear pair was analysed to verify the effectiveness of the method. The geometric parameters and the working conditions of the gear pair are shown in Table I. The threshold of the standard deviation of TE for this pair of gears is $1.0 \times 10^{-5} / \mathrm{rad}$.

Table I: Parameters of geometry and working condition.

\begin{tabular}{|l|l|c|}
\hline \multirow{2}{*}{ Number of teeth } & Drive gear & 23 \\
\cline { 2 - 3 } & Driven gear & 34 \\
\hline Modulus $\boldsymbol{m}$ & Drive gear: $\mathrm{x} 1$ & 4 \\
\hline Pressure angle $\boldsymbol{\alpha}\left(^{\circ}\right)$ & 0.2322 \\
\hline \multirow{2}{*}{$\begin{array}{l}\text { Modification } \\
\text { coefficient }\end{array}$} & Driven gear: $\mathrm{x} 2$ & 0.0259 \\
\hline \multirow{2}{*}{ Tooth width $(\mathrm{mm})$} & Drive gear: B1 & 20 \\
\cline { 2 - 3 } & Driven gear: B2 & 20 \\
\hline The rotate speed of drive gear (r/min) & 1080 \\
\hline The torque of drive gear (Nm) & 221 \\
\hline \multicolumn{2}{|l|}{ Load factor } & 1.557 \\
\hline
\end{tabular}

\subsection{Simulation analysis of the gear pair with tooth profile modification}

The simulation analysis of meshing for the modified gear pair was conducted and the meshing characteristics were investigated. The contour map of the equivalent stress during the meshing process is shown in Fig. 7.

The contact stress gradually increases from zero to maximum when the tooth pair starts meshing. Thereafter, the gear pair enters into the single tooth meshing status, wherein the contact stress maintains the maximum during this time until it enters into the status of double teeth meshing. Next, the tooth pair begins to mesh out. The overall trends of the bending stresses are roughly the same with the contact stress. In addition, the difference between the overall trends is that the root stress of the drive gear slowly increases, whereas the bending stress of driven gear slowly decreases when the gear pair is in the single tooth meshing status. Moreover, the maximum values of the contact stress and bending stress on each gear during the transmission, which are main factors that affect the service life of the gear pair, can be 
separately obtained. The contour maps of the contact stress and the bending stress are respectively shown in Figs. 8 and 9, when the gear pair is engaged at the corresponding worst load positions.

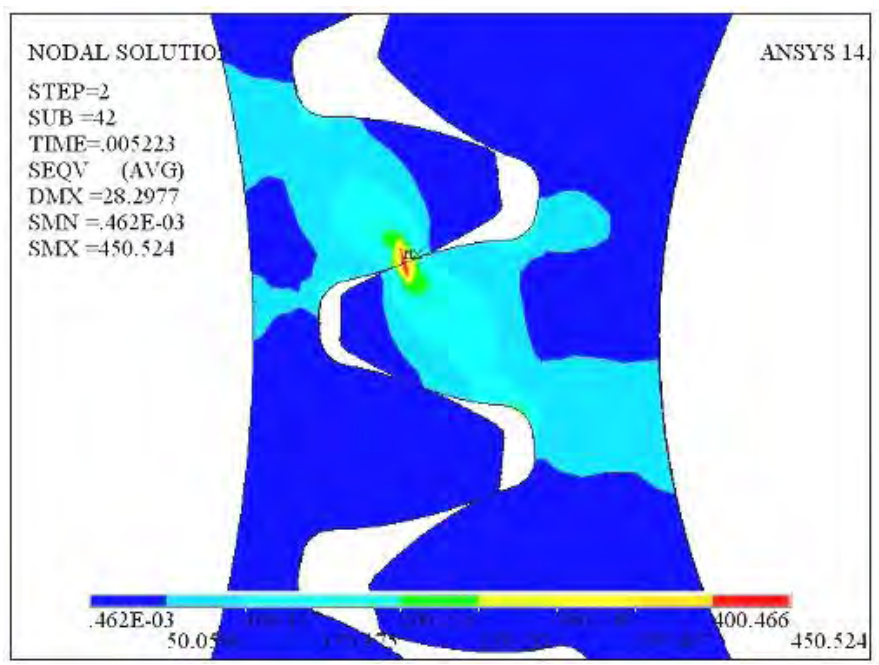

Figure 7: Equivalent stress of the gear pair.

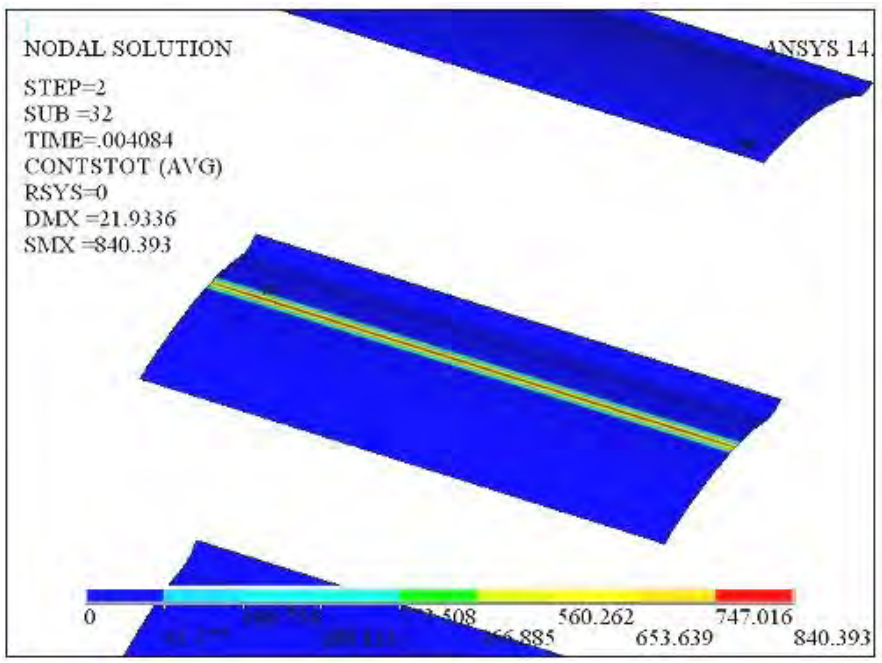

Figure 8: Contour map of the contact stress.

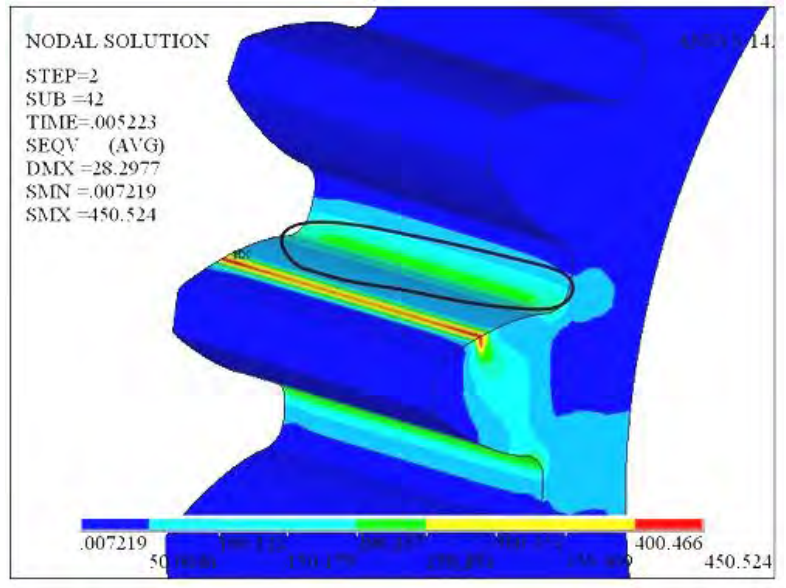

a) Bending stress of the drive gear

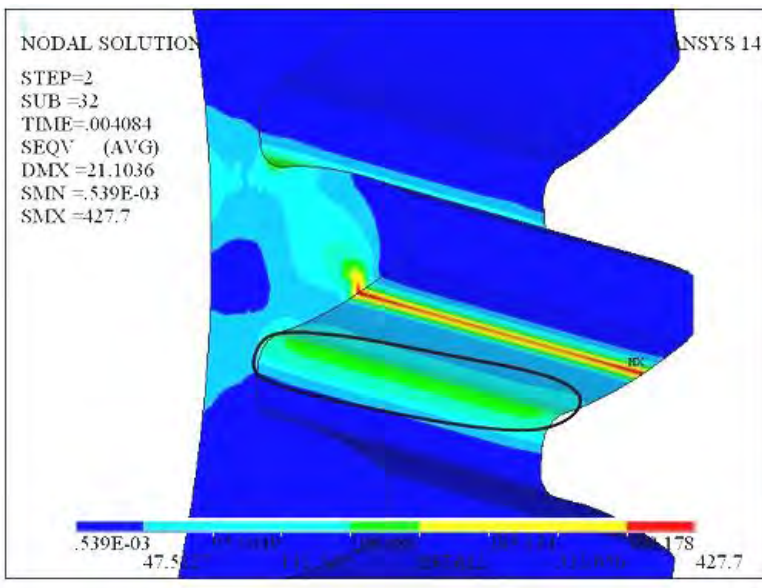

b) Bending stress of the driven gear

Figure 9: Contour maps of bending stress. 
The loads on the contact area between the meshing teeth were read at every load step (Fig. 10). The figure also shows the variation of the load during the meshing process and shows whether the tooth profile modification can solve the problem of impact or not.

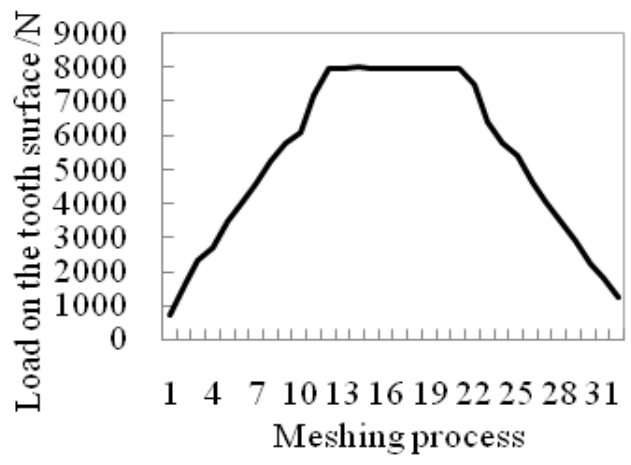

Figure 10: Load on the gear tooth.

\subsection{Optimization of the benchmark curve for tooth profile modification}

Based on the preceding parameters, the modification amount of gears can be calculated based on Eq. (3). The same modification method was used for the two gears in this study because the values of the modification amount for the two gears and their deformations were approximately equal.

Optimization experiments were conducted in this study to find an ideal modification way by optimizing the benchmark curve. Factors and levels of the first orthogonal experiment are listed in Table II.

Table II: Factors and levels of the first orthogonal experiment.

\begin{tabular}{|c|c|c|c|c|}
\hline \multirow{2}{*}{ Levels } & \multicolumn{4}{|c|}{ Factors } \\
\cline { 2 - 5 } & Modification amount $\boldsymbol{\Delta}_{\max }$ & Coefficient $\boldsymbol{\lambda}$ & Power $\boldsymbol{\gamma}$ & Power $\boldsymbol{\beta}$ \\
\hline 1 & 0.01734 & 0.4 & 0.5 & 1.5 \\
\hline 2 & 0.01950 & 0.45 & 0.75 & 1.75 \\
\hline 3 & 0.02167 & 0.5 & 1 & 2 \\
\hline 4 & 0.02384 & 0.55 & 1.25 & 2.25 \\
\hline 5 & 0.02600 & 0.6 & 1.5 & 2.5 \\
\hline
\end{tabular}

Based on Table II and $\mathrm{L}_{25}\left(5^{6}\right), 25$ tests in total were conducted. Different benchmark curves can be established based on the data shown in Table II, in which the gear pair was separately modified with these curves. Thereafter, the simulation of transient meshing was conducted for every test in ANSYS and the results were summarized in Table III.

The results shown in Table III showed that tooth profile modification has no effect on contact stress and bending stress of the gear pair. There are nine sets of tests meet the requirement, their standard deviation of TE are less than $\mathrm{L}_{25}\left(5^{6}\right)$. Therefore, conducting more orthogonal experiments is unnecessary. Table III shows that the TE of the gear pair in test 12 is the smallest. The tooth load distribution during the meshing process in test 12 is shown in Fig. 11 to evaluate the stability of the gear transmission after modification, in which no abrupt load during the meshing process occurred. 
Table III: Result of the first orthogonal experiment.

\begin{tabular}{|c|c|c|c|c|}
\hline \multirow[b]{2}{*}{$\begin{array}{c}\text { Test } \\
\text { number }\end{array}$} & \multicolumn{4}{|c|}{ Results } \\
\hline & $\begin{array}{c}\text { Contact } \\
\text { stress }(\mathrm{MPa})\end{array}$ & $\begin{array}{l}\text { Bending stress of } \\
\text { drive gear }(\mathrm{MPa})\end{array}$ & $\begin{array}{l}\text { Bending stress of } \\
\text { driven gear }(\mathrm{MPa})\end{array}$ & $\begin{array}{c}\text { Standard } \\
\text { deviation of TE } \\
\times 10^{-5} / \mathrm{rad} \\
\end{array}$ \\
\hline 1 & 840.589 & 201.486 & 202.944 & 0.9713 \\
\hline 2 & 840.949 & 202.148 & 202.906 & 0.9888 \\
\hline 3 & 840.433 & 202.541 & 202.926 & 1.2366 \\
\hline 4 & 840.412 & 202.843 & 202.921 & 1.5655 \\
\hline 5 & 840.401 & 203.049 & 202.919 & 1.9030 \\
\hline 6 & 840.452 & 207.465 & 202.887 & 0.9215 \\
\hline 7 & 840.342 & 207.668 & 202.901 & 1.1265 \\
\hline 8 & 840.323 & 207.182 & 202.896 & 1.4322 \\
\hline 9 & 845.571 & 210.484 & 202.895 & 0.9605 \\
\hline 10 & 845.789 & 202.042 & 203.260 & 1.4919 \\
\hline 11 & 853.284 & 212.356 & 202.875 & 1.1333 \\
\hline 12 & 840.393 & 208.014 & 202.870 & 0.7229 \\
\hline 13 & 840.254 & 208.108 & 202.869 & 0.8533 \\
\hline 14 & 845.617 & 205.539 & 203.273 & 1.6412 \\
\hline 15 & 840.377 & 207.785 & 202.891 & 1.1249 \\
\hline 16 & 840.303 & 208.064 & 207.429 & 0.7746 \\
\hline 17 & 840.157 & 208.145 & 206.317 & 0.8649 \\
\hline 18 & 848.368 & 210.503 & 204.289 & 1.7516 \\
\hline 19 & 857.364 & 212.855 & 208.809 & 1.2599 \\
\hline 20 & 840.301 & 207.863 & 207.422 & 1.5135 \\
\hline 21 & 840.477 & 208.156 & 211.736 & 0.7648 \\
\hline 22 & 840.950 & 207.622 & 203.303 & 1.9635 \\
\hline 23 & 840.906 & 207.488 & 211.562 & 2.3917 \\
\hline 24 & 840.210 & 207.902 & 211.743 & 1.6432 \\
\hline 25 & 840.345 & 207.971 & 212.023 & 1.0397 \\
\hline
\end{tabular}

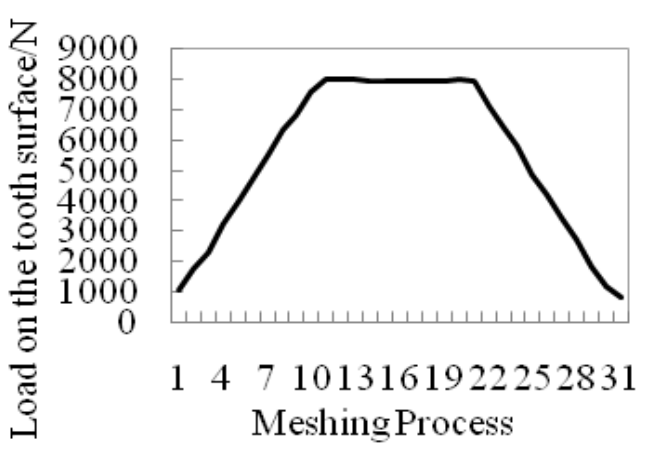

Figure 11: Load on the modified tooth.

Based on the parameters of the tooth profile modification used in test 12 , the ideal benchmark curve for the gear pair specified in Table I can be defined as Eq. (8). 


$$
\Delta=0.02167 \cdot\left[0.45\left(\frac{x}{l}\right)^{1.25}+0.55\left(\frac{x}{l}\right)^{1.5}\right]
$$

\subsection{Comparative analysis}

Simulation analysis and experimental measurement for the standard gear pair with the same parameters shown in Table I were conducted in this study to verify the effects of tooth profile modification on spur gear pair. The simulation results of the gear transmission showed that the trends and values of the contact stress and bending stress for each gear were nearly the same as that in test 12 . The results also showed that tooth profile modification for involute spur gear does not affect the bending stress and contact stress of the gear pair.

The load on gear tooth and its variation law in these two tests are shown in Fig. 12. Fig. 12 shows that the tooth pair without modification could suddenly carry and remove the load when the meshing process starts and exits, and the load on the tooth abruptly increases and decreases when the tooth pair meshes at the alternate points. Therefore, the meshing impact caused by the load mutation is inevitable for standard involute spur gear transmission. The meshing impact is very harmful to the life of the gear pair and could result in an unsteady transmission. However, the load on the modified tooth pair gradually increases and decreases.

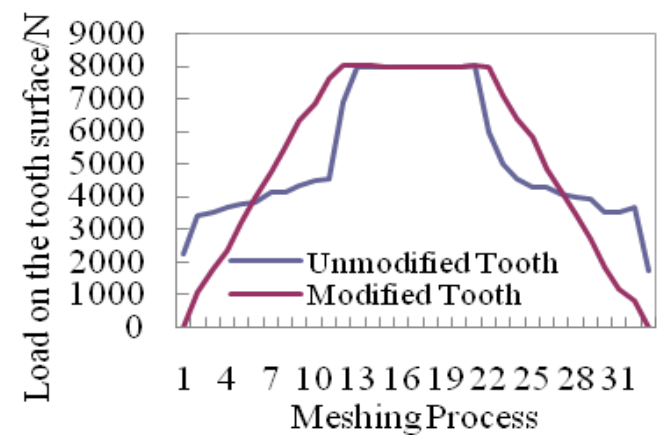

Figure 12: Load on the unmodified and modified tooth.

Furthermore, the TE during the transmission process in these two tests can be described as Fig. 13. The chart visually shows that tooth profile modification is very beneficial to decrease the fluctuation of TE which results from tooth deformation and impact, thereby solving the problem of vibration and noises.

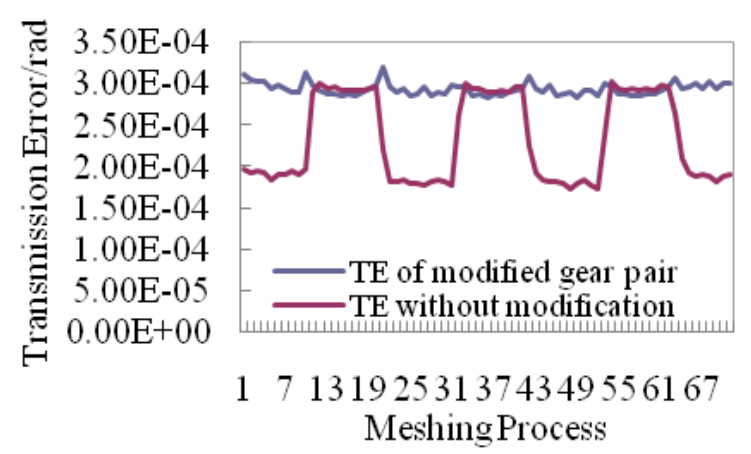

Figure 13: Line chart of the TE.

In this study, the simulation of transient meshing and experimental measurements were also conducted for the gear pairs which were modified with other universal benchmark curves, such as Hidaka-Terauchi curve, Walker's curve as well as Akiyama-Utagawa curve. The variation curves of loads on the gear teeth which were modified with different benchmark curves can be seen in Fig. 14. 


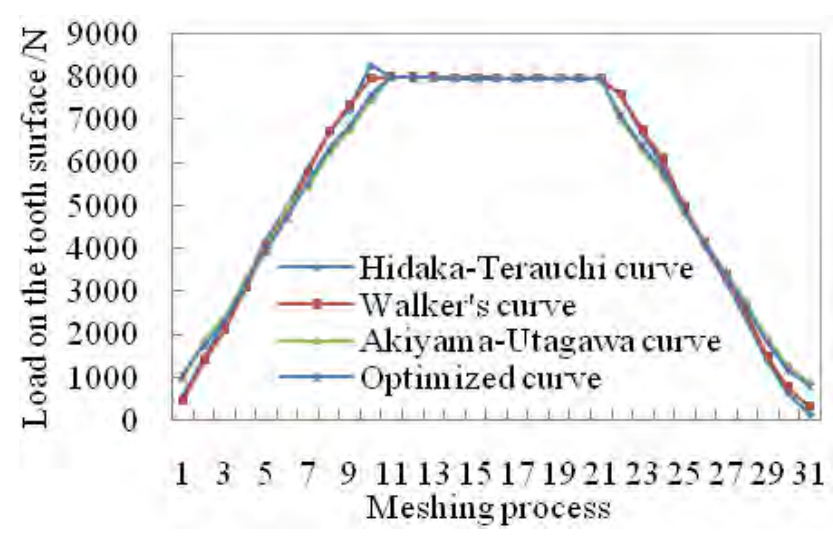

Figure 14: Loads on the gear teeth with different benchmark curves.

All of these modification methods can solve the problem of impact to a certain extent. However, Fig. 14 shows that the loads on the teeth which are modified by the optimized curve and the Hidaka-Terauchi curve are more stable.

In addition, the contact stress and bending stress of the gear with different benchmark curves were respectively extracted in this study and their standard deviations of TE were separately calculated. The results are shown in the form of a histogram as shown in Fig. 15.

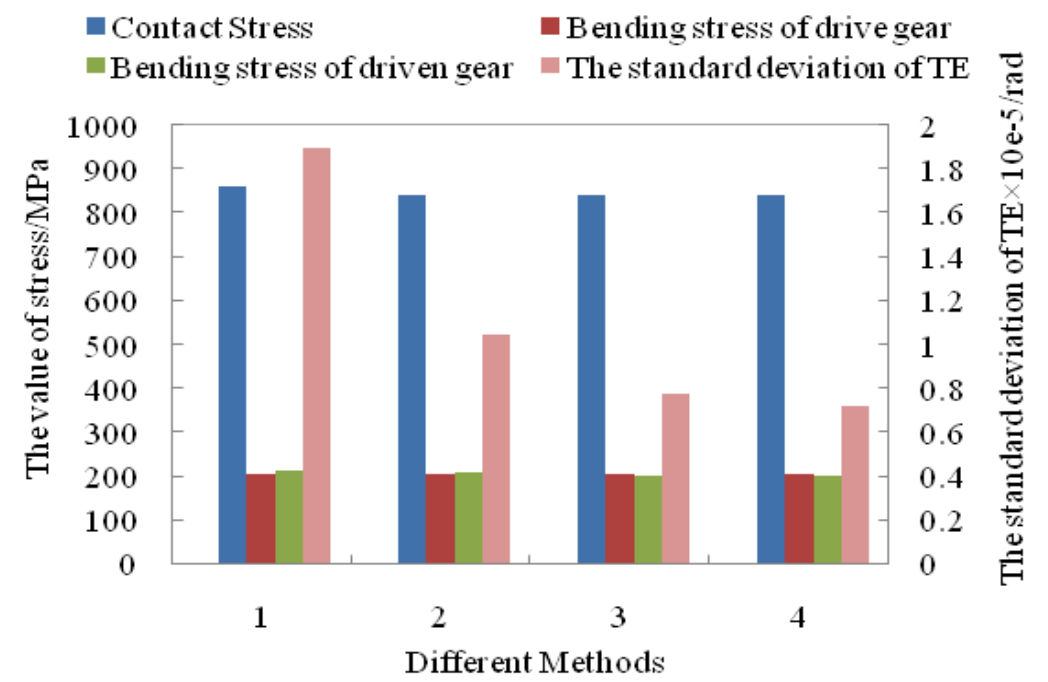

Figure 15: Histogram of analysis results in different methods.

The number on the horizontal axis represents different methods. Especially, 1 4 represent the four modification methods with Hidaka-Terauchi curve, Walker's curve, AkiyamaUtagawa curve, and optimized curve, respectively. The results show that different modification methods have no effect on the stress of the gear. However, different modification methods have great influence on the standard deviation of TE. Among these, the value obtained by the method with the optimized curve is the smallest, which indicates the most stable transmission.

\section{CONCLUSIONS}

A method of tooth profile modification based on the composite benchmark curve was proposed in this study and the corresponding modification parameters were optimized by orthogonal experiments to improve the stability and precision of spur gear transmission. After a series of simulation and comparative analysis, the meshing characteristics of the modified gear pair were obtained. In addition, the difference between these methods was acquired by 
comparing with other modification methods. The following conclusions can be drawn from this study:

(1) Tooth profile modification for the involute spur gear pair does not substantially affect the distribution and variation of the contact stress and bending stress. However, this modification can effectively improve the stability of the transmission.

(2) After the gear pair is modified, the load carried by tooth pair gradually increases and decreases during the meshing process. Therefore, the impact and noise in the process of gear transmission can be greatly reduced.

(3) Tooth profile modification can effectively reduce the fluctuation of TE of the involute spur gear mechanism because of the deformation of gear teeth and the impact of the shock, which is of great significance to improve the accuracy of the gear transmission.

(4) The performance of the gear pair with tooth profile modification mainly depends on the shape of the benchmark curve. Compared with existing methods, the proposed method can obtain the optimum benchmark curve for tooth profile modification based on the structure and working condition of the involute spur gear mechanism and can simulate and evaluate the transmission performance of the modified gear pair.

The present study is significant in finding an ideal way of tooth profile modification for involute spur gear pair. And the method of checking the intensity as well as assessing the modification effects is proposed.

However, the proposed method was aimed at the spur gear transmission, which cannot be directly applied to the helical cylindrical gear mechanism and bevel gear mechanism. In addition, the fatigue analysis of the gear pair was not conducted in this study. These are the focus of future research.

\section{ACKNOWLEDGEMENT}

This work was supported by the National Natural Science Foundation of China (Grant No. 51375282 \& 51674155), the Special Funds for Cultivation of Taishan Scholars, the Shandong Provincial Natural Science Foundation of China (Grant No. ZR2015EM017 \& ZR2014EEM021), the Science and Technology Development Program of Shandong Province (Grant No. 2014GGX103043), and the Innovation Foundation for Graduate Students of Shandong University of Science and Technology (Grant No. YC150211).

\section{REFERENCES}

[1] Kim, J. S.; Park, N. G.; Lee, H. W. (2015). Tooth modification for optimizing gear contact of a wind-turbine gearbox, Proceedings of the Institution of Mechanical Engineers, Part C: Journal of Mechanical Engineering Science, Vol. 230, No. 7-8, 1318-1330, doi:10.1177/ 0954406215622656

[2] Magalhaes, L.; Martins, R. ; Locateli, C.; Seabra, J. (2011). Influence of tooth profile on gear power loss, Industrial Lubrication and Tribology, Vol. 63, No. 1, 27-33, doi:10.1108/ $\underline{00368791111101812}$

[3] Magalhaes, L.; Martins, R.; Locateli, C.; Seabra, J. (2010). Influence of tooth profile and oil formulation on gear power loss, Tribology International, Vol. 43, No. 10, 1861-1871, doi:10.1016/j.triboint.2009.10.001

[4] Gevigney, J. D.; Ville, F.; Changenet, C.; Velex, P. (2013). Tooth friction losses in internal gears: Analytical formulation and applications to planetary gears, Proceedings of the Institution of Mechanical Engineers, Part J: Journal of Engineering Tribology, Vol. 227, No. 5, 476-485, doi: $10.1177 / 1350650112470059$

[5] Jamali, H. U.; Sharif, K. J.; Evans, H. P.; Snidle, R. W. (2015). The transient effects of profile modification on elastohydrodynamic oil films in helical gears, Tribology Transactions, Vol. 58, No. 1, 119-130, doi: $10.1080 / 10402004.2014 .936990$ 
[6] Shanmugasundaram, S.; Muthusamy, N. (2011). Profile modification - a design approach for increasing the tooth strength in spur gear, The International Journal of Advanced Manufacturing Technology, Vol. 55, No. 1, 1-10, doi:10.1007/s00170-010-3034-3

[7] Velex, P.; Chapron, M.; Fakhfakh, H.; Bruyère, J.; Becquerelle, S. (2016). On transmission errors and profile modifications minimising dynamic tooth loads in multi-mesh gears, Journal of Sound and Vibration, Vol. 379, 28-52, doi:10.1016/j.jsv.2016.05.044

[8] Ghosh, S. S.; Chakraborty, G. (2015). Parametric instability of a multi-degree-of-freedom spur gear system with friction, Journal of Sound and Vibration, Vol. 354, 236-253, doi:10.1016/j.jsv.2015.06.012

[9] Subramanian, R. B.; Srinivasan, K. (2014). Vibration analysis of an influence of groove in the bottom land of a spur gear, Journal of Vibration and Control, Vol. 20, No. 6, 847-858, doi: $10.1177 / 1077546312471363$

[10] Bahk, C.-J.; Parker, R. G. (2013). Analytical investigation of tooth profile modification effects on planetary gear dynamics, Mechanism and Machine Theory, Vol. 70, 298-319, doi:10.1016/ j.mechmachtheory.2013.07.018

[11] Motahar, H.; Samani, F. S.; Molaie, M. (2016). Nonlinear vibration of the bevel gear with teeth profile modification, Nonlinear Dynamics, Vol. 83, No. 4, 1875-1884, doi:10.1007/s11071-015$2452-\mathrm{Z}$

[12] Artoni, A.; Guiggiani, M.; Kahraman, A.; Harianto, J. (2013). Robust optimization of cylindrical gear tooth surface modifications within ranges of torque and misalignments, Journal of Mechanical Design, Vol. 135, No. 12, 9 pages, doi:10.1115/1.4025196

[13] Ghribi, D.; Bruyère, J.; Velex, P.; Octrue, M.; Haddar, M. (2012). A contribution to the design of robust profile modifications in spur and helical gears by combining analytical results and numerical simulations, Journal of Mechanical Design, Vol. 134, No. 6, 9 pages, doi:10.1115/ 1.4006740

[14] Sachidananda, H. K.; Raghunandana, K.; Gonsalvis, J. (2015). Design of spur gears using profile modification, Tribology Transactions, Vol. 58, No. 4, 736-744, doi:10.1080/10402004. 2015.1010762

[15] Barbieri, M.; Zippo, A.; Pellicano, F. (2014). Adaptive grid-size finite element modeling of helical gear pairs, Mechanism and Machine Theory, Vol. 82, 17-32, doi:10.1016/ j.mechmachtheory.2014.07.009

[16] Tesfahunegn, Y. A.; Rosa, F.; Gorla, C. (2010). The effects of the shape of tooth profile modifications on the transmission error, bending, and contact stress of spur gears, Proceedings of the Institution of Mechanical Engineers, Part C: Journal of Mechanical Engineering Science, Vol. 224, No. 8, 1749-1758, doi:10.1243/09544062JMES1844

[17] Litvin, F. L.; Fuentes, A. (2004). Gear Geometry and Applied Theory, $2^{\text {nd }}$ ed., Cambridge University Press, Cambridge

[18] Wang, Z. H. (2013). Simulation of hypoid gears dynamic performance, Science Press, Peking (in Chinese)

[19] Xie, M.-Y.; Aw, K.; Edwards, B.; Gao, W.; Hu, P. (2014). Orthogonal experimental design of polydimethylsiloxane curing for the design of low-frequency vibrational energy harvester, Journal of Intelligent Material Systems and Structures, Vol. 25, No. 18, 2228-2234, doi: $\underline{10.1177 / 1045389 \times 14538536}$ 